\title{
Hereditary prostate cancer in African American families: linkage analysis using markers that map to five candidate susceptibility loci
}

\author{
WM Brown', EM Lange', H Chen ${ }^{2,3,4}$, SL Zheng ${ }^{5}$, B Chang ${ }^{5}$, KE Wiley ${ }^{6}$, SD Isaacs ${ }^{6}$, PC Walsh ${ }^{6}$, WB Isaacs ${ }^{6}$, \\ $J \mathrm{Xu}^{1,5}$ and KA Cooney, ${ }^{*, 2,3}$
}

'Department of Public Health Sciences, Wake Forest University School of Medicine, Winston-Salem, NC 27I 57, USA; ${ }^{2}$ Department of Internal Medicine, University of Michigan Medical School, Ann Arbor, MI 48109, USA; ${ }^{3}$ Department of Urology, University of Michigan Medical School, Ann Arbor, MI 48I 09 , USA; ${ }^{4}$ Ann Arbor Department of Veteran's Affairs, Ann Arbor, MI 48109, USA; ${ }^{5}$ Center for Human Genomics, Wake Forest University School of Medicine, Winston-Salem, NC 27I57, USA; ${ }^{6}$ Brady Urological Institute, Johns Hopkins Hospital, Baltimore, MD 2I 287, USA

African American men have the highest incidence of prostate cancer in the world. Despite this statistic, linkage studies designed to localise prostate cancer susceptibility alleles have included primarily men of Caucasian descent. In this report, we performed a linkage analysis using 33 African American prostate cancer families from two independent research groups. In total, 126 individuals (including 89 men with prostate cancer) were genotyped using markers that map to five prostate cancer susceptibility loci, namely HPCI at I q24-25, PCAP at Iq42.2-43, CAPB at I 36, HPC20 on chromosome 20, and HPCX at Xq27-28. Multipoint mode-of-inheritancefree linkage analyses were performed using the GENEHUNTER software. Some evidence of prostate cancer was detected to HPCI using all families with a maximum NPL Z score of I. 12 near marker D I S4 I 3 ( $P=0.13$ ). Increased evidence of linkage was observed in the 24 families with prostate cancer diagnosis prior to age 65 years and in the 20 families with male-to-male transmission. Some evidence of prostate cancer linkage was also detected at markers mapping to PCAP, HPC20, and HPCX. Continued collection and analysis of African American prostate cancer families will lead to an improved understanding of inherited susceptibility in this high-risk group.

British Journal of Cancer (2004) 90, 5I0-5|4. doi:I0.1038/sj.bjc.660I4I7 www.bjcancer.com

(c) 2004 Cancer Research UK

Keywords: prostate cancer; linkage analysis; hereditary cancer syndromes

Prostate cancer has a higher incidence and mortality among African American men compared to men of all other racial and ethnic groups living in the US (Jemal et al, 2002). The explanation for this observation is uncertain and may be due to a combination of dietary, environmental and genetic factors. Family history has been shown to be a strong risk factor for prostate cancer (see review in Bratt, 2002), and this has led many research teams to collect large prostate cancer families with the goal of identifying prostate cancer susceptibility genes using linkage analysis. Review of most published data, however, describes linkage evidence primarily for Caucasian multiplex prostate cancer families identified in North America and/or Europe.

Several population-based studies performed in the US and Canada have demonstrated that the relative risk of prostate cancer attributed to a family history of prostate cancer is similar between individuals of African and Caucasian descent (Hayes et al, 1995; Monroe et al, 1995; Whittemore et al, 1995). For example, Whittemore et al (1995) reported data from a population-based case-control study of prostate cancer among individuals of

*Correspondence: Dr Kathleen A Cooney, 7310 CCGC, 1500 East Medical Center Drive, Ann Arbor, MI 48I09-0946, USA;

E-mail: kcooney@umich.edu

Received 4 February 2003; revised I 4 July 2003; accepted 20 September 2003
African-, Caucasian-, and Asian descent from Los Angeles, San Francisco, Hawaii, Vancouver, and Toronto. In their study, the odds ratio associated with a family history of prostate cancer was 3.2 for individuals of African American descent (95\% confidence interval 2.0 -5.0) and 1.9 for individuals of Caucasian descent $(95 \%$ confidence interval 1.2-1.9). Given the importance of prostate cancer in African American families and the fact that the family history is a significant risk factor for disease in this racial group, we set out to study a set of multiplex prostate cancer families for linkage to five previously reported prostate cancer susceptibility loci: namely HPC1 at 1q24-25 (MIM 601518) (Smith et al, 1996), $P C A P$ at 1q42.2-43 (MIM 602759) (Berthon et al, 1998), CAPB at 1p36 (MIM 603688) (Gibbs et al, 1999), HPC20 on chromosome 20 (Berry et al, 2000b), and HPCX at Xq27-28 (MIM 300147) (Xu et al, 1998).

\section{MATERIAL AND METHODS}

\section{Patient selection}

A total of 33 African American families, including 19 families from the University of Michigan Prostate Cancer Genetics Project (PCGP) and 14 families from the Johns Hopkins University (JHU) Family Collection, were analysed in this report. Each family has a minimum of two genotyped affected men with prostate cancer in a 
Table I Map position of markers used in prostate cancer linkage analysis for the four candidate regions on chromosomes I and X

\begin{tabular}{|c|c|c|c|c|c|c|c|}
\hline CAPB & Map position (cM) & HPCI & Map position (cM) & PCAP & Map position (cM) & HPCX & Map position (cM) \\
\hline DIS489 & 29.9 & DIS452 & 188.9 & $D / S 2678$ & 256.3 & DXSI 205 & 87.6 \\
\hline D/SI597 & 29.9 & $D / S 2 / 2$ & 193.8 & $D / S 2670$ & 263.0 & DXS 1200 & 96.4 \\
\hline DIS402 & 31.0 & DIS466 & 198.3 & D/S2785 & 266.3 & DXS1193 & 97.9 \\
\hline DIS407 & 33.8 & $D / S / 58$ & 200.6 & DIS321 & 267.5 & $D X S 1113$ & 98.1 \\
\hline D/S3669 & 37.1 & DIS422 & 205.4 & D/S304 & 267.5 & DXS1/108 & 104.3 \\
\hline DIS552 & 45.3 & $D / S 4 / 3$ & 212.4 & D/S2842 & 273.5 & & \\
\hline
\end{tabular}

first- and/or second-degree relationship. For the 19 PCGP families, all cases of prostate cancer were confirmed through review of medical records or by independent report of two family members, and all protocols were reviewed and approved by the University of Michigan Institutional Review Board. Subsets of these families have been included in prior linkage reports from our research team (Cooney et al, 1997; Lange et al, 1999; Bock et al, 2001). A total of 14 families were identified at the Brady Urology Institute at JHU primarily through physician referral. The affection status and age at diagnosis were confirmed either through medical records or from two other independent sources. All participants gave full informed consent and protocols were approved by the Johns Hopkins University Institutional Review Board. Subsets of these families have been included in prior linkage reports (Smith et al, 1996;Xu et al, 1998, 2001).

\section{Laboratory methods}

Genotyping was performed by either PCR using radiolabelled PCR primers and acrylamide gel electrophoresis (Cooney et al, 1997) or using fluorescently labelled makers with PCR products run on ABI DNA sequencers (Smith et al, 1996). A common DNA CEPH control (1347-02) was used to standardise allele sizes across experiments. Marker selection and map position for loci on chromosomes 1 and $\mathrm{X}$ are provided in Table 1 . The panel of HPC20 markers used in the current study was nearly identical to those reported in Berry et al (Berry et al, 2000b) and are shown in Figure 1. Marker positions were determined by the Mammalian Genotyping Service (MGS) website (http://research.marshfieldclinic.org/genetics/Map_Markers/maps/IndexMapFrames.html).

\section{Statistical analyses}

Multipoint mode-of-inheritance-free linkage analyses were performed using the statistical software package GENEHUNTER versions 1.3. (for chromosome $\mathrm{X}$ ) and $2.0 \beta$ (for chromosomes 1 and 20) (Kruglyak et al, 1996). The marker allele frequencies were estimated from the data using all genotyped individuals. Results are reported in terms of standardised $Z$ scores and their associated $P$-values. In addition to analyses of the complete set of pedigrees, stratified analyses were also performed on the subsets of pedigrees using previously defined cutoff values for average age-of-diagnosis of genotyped affected individuals, number of confirmed affected individuals, and classification of male-to-male disease transmission.

\section{RESULTS}

A total of 126 individuals (including 89 confirmed prostate cancer cases) were genotyped and included in the analyses. The clinical characteristics of the families are described in Table 2. Seven of 33 families had very early-onset prostate cancer with an average age of prostate cancer diagnosis within the family (based on ages of

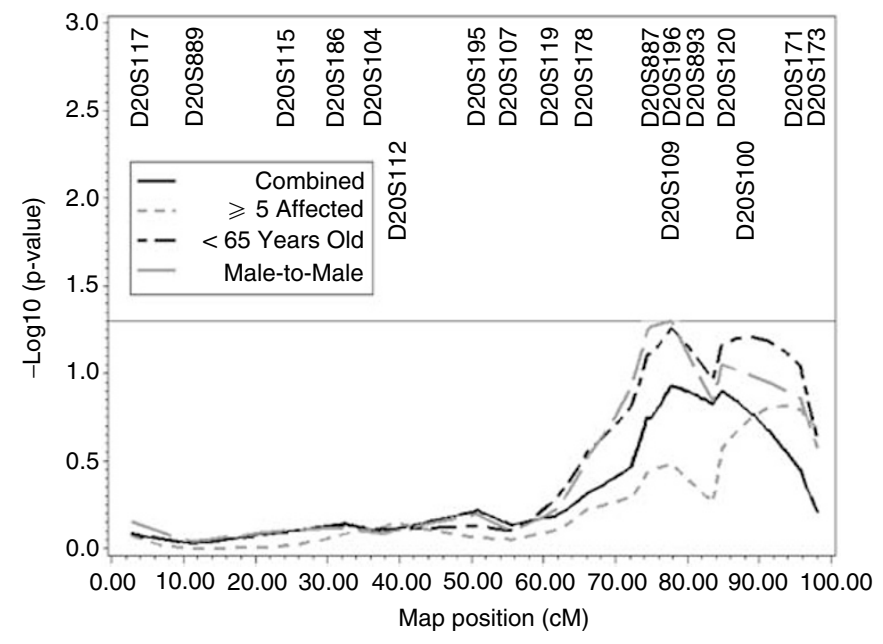

Figure I Linkage analysis using markers that span chromosome 20. Markers used for this analysis are illustrated across the top of the figure, and their map position is depicted across the bottom. For all 27 families as well as each stratification, $-\log 10$ of the $P$-value is plotted on the $y$-axis. Only the stratifications of $\geqslant 5$ affecteds, age at diagnosis $<65$ years, and maleto-male transmission are shown.

men available for genotyping) of $<55$ years. Note that 20 out of 33 or $61 \%$ of families had evidence of disease transmission from father to son that would be inconsistent with prostate cancer risk being transmitted from the $\mathrm{X}$ chromosome.

Three regions of chromosome 1 were assessed for prostate cancer linkage using a panel of polymorphic markers within each region corresponding to the $C A P B, H P C 1$, and $P C A P$ putative susceptibility genes. Some evidence in support of prostate cancer linkage was observed in the HPC1 candidate region with a maximum multipoint NPL $Z$ score of $1.12(P=0.13)$ near marker D1S413 (Table 3). The evidence for linkage was greater in the 24 families with an average age of prostate cancer diagnosis $<65$ years $(Z=1.68$ near marker D1S413; $P=0.05)$ and the 20 families with male-to-male transmission $(Z=1.73$ near marker D1S413; $P=0.04)$. The highest NPL $Z$ score for the PCAP locus was observed in the subset of 24 families with an average age of prostate cancer diagnosis $<65$ years (maximum multipoint NPL $Z$ score of 1.48 near $D 1 S 2785, P=0.07$ ). The multipoint NPL $Z$ scores for markers corresponding to the $C A P B$ locus were largely negative.

A panel of chromosome 20 markers spanning nearly the entire chromosome was used to assess the degree of linkage to HPC2O given the less exact location for this prostate cancer susceptibility locus (Figure 1). Genotype data was available for 27 of the 33 families. The maximum multipoint NPL $Z$ score for the entire set of African American prostate cancer families was 1.17 near marker D20S893 $(P=0.12)$ (Table 4). However, as with $H P C 1$, increased evidence of prostate cancer linkage was observed in the families 
Table 2 Characteristics of African American prostate cancer families

\begin{tabular}{|c|c|c|c|c|c|c|}
\hline & $\begin{array}{l}\text { No. of } \\
\text { families }\end{array}$ & $\begin{array}{l}\text { Ave. no. of } \\
\text { confirmed affected } \\
\text { men/family }\end{array}$ & $\begin{array}{c}\text { Ave. no. of } \\
\text { confirmed affected } \\
\text { men genotyped/family }\end{array}$ & $\begin{array}{l}\text { Ave. age at } \\
\text { diagnosis of } \\
\text { cases/family }\end{array}$ & $\begin{array}{l}\text { No. Families with } \\
\text { ave. age at diagnosis } \\
65 \text { years }^{\mathrm{a}}\end{array}$ & $\begin{array}{l}\text { No. families with } \\
\text { male-to-male } \\
\text { transmission }\end{array}$ \\
\hline University of Michigan PCGP & 19 & $4.4 \pm 2.4$ & $2.5 \pm 0.7$ & $60.8 \pm 6.6$ & 13 & 12 \\
\hline JHU family collection & 14 & $5.4 \pm 3.5$ & $3.1 \pm 1.5$ & $59.5 \pm 6.8$ & $\mid 1$ & 8 \\
\hline
\end{tabular}

aBased on those men available for genotyping.

Table 3 Summary of mode-of-inheritance-free linkage analyses using markers that map to the three candidate loci on chromosome I

\begin{tabular}{|c|c|c|c|c|}
\hline $\begin{array}{c}\text { Chromosome I } \\
\text { Families }\end{array}$ & $\begin{array}{c}\text { No. of } \\
\text { families }\end{array}$ & Max NPL & $P$-value & $\begin{array}{l}\text { Nearest } \\
\text { marker }\end{array}$ \\
\hline \multicolumn{5}{|l|}{ Region I: CAPB } \\
\hline All & 32 & -0.20 & 0.58 & DIS552 \\
\hline$=>5$ affected & 13 & -0.28 & 0.59 & DIS552 \\
\hline$<5$ affected & 19 & -0.03 & 0.51 & DIS552 \\
\hline$=>65$ years & 8 & -0.01 & 0.52 & DIS552 \\
\hline$<65$ years & 24 & -0.23 & 0.59 & DIS552 \\
\hline Male-to-male & 20 & -0.23 & 0.58 & DIS552 \\
\hline Non male-to-male & 12 & -0.04 & 0.51 & DIS552 \\
\hline \multicolumn{5}{|l|}{ Region 2: HPCI } \\
\hline All & 32 & 1.12 & 0.13 & DIS4I3 \\
\hline$=>5$ affected & 13 & 0.75 & 0.22 & $D / 5413$ \\
\hline$<5$ affected & 19 & 0.91 & 0.18 & $D / S 158$ \\
\hline$=>65$ years & 8 & -0.03 & 0.52 & DIS552/D/S452 \\
\hline$<65$ years & 24 & 1.68 & 0.05 & DIS4I3 \\
\hline Male-to-male & 20 & 1.73 & 0.04 & DIS4I3 \\
\hline Non male-to-male & 12 & -0.02 & 0.50 & DIS552/D/S452 \\
\hline \multicolumn{5}{|l|}{ Region 3: PCAP } \\
\hline All & 32 & 0.59 & 0.27 & DIS2785 \\
\hline$=>5$ affected & 13 & 0.37 & 0.34 & DIS4I3/DIS2678 \\
\hline$<5$ affected & 19 & 0.88 & 0.18 & DIS2785 \\
\hline$=>65$ years & 8 & -0.67 & 0.73 & DIS4I3/DIS2678 \\
\hline$<65$ years & 24 & 1.48 & 0.07 & DIS2785 \\
\hline Male-to-male & 20 & 0.88 & 0.18 & DIS4/3/DIS2678 \\
\hline Non male-to-male & 12 & -0.07 & 0.52 & DIS321 \\
\hline
\end{tabular}

Data from the marker with the most positive NPL $Z$ score are provided. Rows that are in bold text indicate NPL $Z$ scores that are associated with statistically significant $P$-values $(P<0.05)$. One PCGP family was not genotyped for chromosome I markers.

with male-to-male transmission $(Z=1.64 ; P=0.05)$ and with average age of prostate cancer diagnosis less than age 65 years $(Z=1.60 ; P=0.05)$ near the same marker. Increased evidence of linkage was also detected in the families with fewer than five affected family members near marker $D 20 S 120(Z=1.46, P=0.07)$.

The overall evidence of prostate cancer linkage to $H P C X$ was weakly positive with a maximum NPL $Z$ score of 1.20 near marker DXS1205 $(P=0.12)$ in 30 families. Note that two additional families were removed from this analysis because all affected individuals in these pedigrees could not share the same $\mathrm{X}$ chromosome (e.g. paternal uncle and nephew pairs). None of the stratifications provided increased evidence in support of $H P C X$ compared to the entire set of families.

\section{DISCUSSION}

This is the first report of prostate cancer linkage to putative prostate cancer susceptibility loci using only families who are of African American descent. Previous studies, including several from our own research groups, have addressed potential prostate cancer susceptibility loci in African American families through
Table 4 Summary of mode-of-inheritance-free linkage analyses using markers that map to the HPC20 and HPCX candidate regions

\begin{tabular}{|c|c|c|c|c|}
\hline & $\begin{array}{c}\text { No. of } \\
\text { families }\end{array}$ & $\begin{array}{l}\text { Max } \\
\text { NPL }\end{array}$ & $P$-value & $\begin{array}{c}\text { Nearest } \\
\text { marker }\end{array}$ \\
\hline \multicolumn{5}{|c|}{ Chromosome 20 families } \\
\hline All & 27 & 1.17 & 0.12 & D20S893 \\
\hline$=>5$ affected & 11 & 1.02 & 0.15 & D20S17I \\
\hline$<5$ affected & 16 & 1.46 & 0.07 & D2OS 120 \\
\hline$=>65$ years & 7 & 0.58 & 0.28 & D20S195 \\
\hline$<65$ years & 20 & 1.60 & 0.05 & D20S893 \\
\hline Male-to-Male & 17 & 1.64 & 0.05 & D20S893 \\
\hline Non male-to-male & 10 & 0.33 & 0.36 & D20S/86 \\
\hline \multicolumn{5}{|c|}{ Chromosome $X$ families } \\
\hline All & 30 & 1.20 & 0.12 & DXS1205 \\
\hline$=>5$ affected & 12 & 0.77 & 0.21 & DXS 1200 \\
\hline$<5$ affected & 18 & 1.09 & 0.15 & DXS1205 \\
\hline$=>65$ years & 8 & 0.83 & 0.17 & DXS 1205 \\
\hline$<65$ years & 22 & 0.77 & 0.19 & DXS 1200 \\
\hline Male-to-male & 18 & 0.84 & 0.22 & DXSI205 \\
\hline Non male-to-male & 12 & 0.86 & 0.20 & DXS1205 \\
\hline
\end{tabular}

Data from the marker with the most positive NPL Z score is provided. Rows that are in bold text indicate NPL $Z$ scores that are associated with statistically significant $P$ values $(P<0.05)$. Note that six PCGP families were not genotyped for chromosome 20 markers and one PCGP family was not genotyped for chromosome $X$ markers.

stratification of large family data sets according to race. In this report, we have combined two sets of African American pedigrees from the University of Michigan PCGP and the JHU Family Collection. While a subset of these pedigrees have been studied previously, reanalysing the data in a combined analysis facilitates stronger conclusions regarding evidence for linkage to the described candidate regions in African Americans. The number of pedigrees has been expanded since the original reports, and we have attempted to use common markers for each locus. Furthermore, the increased number of pedigrees enables subset analyses incorporating only African American pedigrees. Subsetting pedigrees based on numbers of confirmed affected men, age at diagnosis, and evidence of male-to-male transmission has been invaluable in helping to localise candidate regions for prostate cancer susceptibility genes. Small individual collections of African American pedigrees have, until now, made the approach of stratified analyses infeasible. The increased number of pedigrees also enables better estimates of allele frequencies in the African American population to be used in these analyses. This is relevant since allele frequencies may vary according to race, and misspecification of allele frequencies may lead to spurious linkage results. Finally, trying to piece together results from nonparametric linkage analysis across different studies to assess the total evidence for linkage is problematic. NPL $Z$ scores are nonadditive, and thus the evidence for linkage cannot be simply summed up over all studies. While cumulative $Z$ scores may be determined if the number of pedigrees in each study is known, calculating the degree of statistical significance ( $P$-value) is far more difficult. Taken together, there is a definite benefit to examining sets of 
pedigrees together as demonstrated by the analyses presented in this report.

HPC1 at 1q24-25 has been the most widely studied prostate cancer susceptibility locus. Although there have been both positive and negative linkage reports, a meta-analysis using 772 hereditary prostate cancer families from throughout the world revealed some evidence for prostate cancer linkage with a peak NPL $Z$ score of 1.14 at $D 1 S 212(\mathrm{Xu}, 2000)$. In this meta-analysis, the 491 families with evidence of male-to-male disease transmission revealed increased evidence for linkage with a peak NPL score of 2.30 at D1S452. Review of earlier HPC1 linkage reports suggests that African American prostate cancer families may have evidence of disease linkage to 1q24-25 markers. In the Smith et al (1996) study, the two African American families studied had a combined LOD score of 1.4. This was followed up in a report from the University of Michigan PCGP describing disproportionate evidence for 1q24-25 linkage in six African American families from the total sample of 59 families (Cooney et al, 1997). Our current combined analysis is consistent with these earlier reports with evidence for linkage to HPC1 in 32 families (for which genotype data was available) studied together, as well as increased evidence for linkage in families with early-onset disease and in families with male-to-male transmission. Previous work from Gronberg et al (1997) has emphasised that young age at diagnosis may be a feature of HPC1-related prostate cancers. Recently, RNASEL has been proposed to be a candidate for HPC1 (Carpten et al, 2002), and a single African American prostate cancer family has been shown to have a mutation in the initiating methionine occurring in four of six brothers with prostate cancer. Sequencing of 16 African American probands from a set of University of Michigan PCGP families failed to identify this M1I or any other RNASEL mutations (Chen et al, 2002), Further studies should be performed to specifically test the role of RNASEL mutations in African American prostate cancer families.

The two other prostate cancer susceptibility loci on chromosome 1 have not been specifically studied in African American prostate cancer families, although the $14 \mathrm{JHU}$ families were included in a previously published analysis of all three chromosome 1 loci (Xu et al, 2001). The CAPB locus at 1 p36 was described by Gibbs et al (1999) in families with an excess of prostate cancer as well as one or more cases of brain cancer in a first- and/or second-degree relative. Review of the pedigrees from the 33 African American families described in this report reveals no cases of primary brain cancer in first- and/or second-degree relatives. Most of the linkage evidence in support of the PCAP locus at 1q42-43 is derived from families from France and England (Berthon et al, 1998; Cancel-Tassin et al, 2001); many of the published prostate cancer linkage studies in other populations have not provided significant support for this putative locus (for example, Berry et al, 2000a; Xu et al, 2001). In our study of 32 African American families in which genotype data was available, we did not see significant evidence for linkage. However, the 24 families with average age of prostate cancer diagnosis less than age 65 years revealed some evidence for linkage with an NPL $Z$ score of 1.48 near marker D1S2785 $(P=0.07)$. This is the same strata that contributed significantly to the observation of prostate cancer linkage in families from Southern and Western Europe (CancelTassin et al, 2001). Given the likelihood of locus heterogeneity for prostate cancer, stratification by clinical phenotype (including other cancers segregating in families and young age at diagnosis) may help to elucidate the prostate cancer susceptibility genes relevant to specific types of prostate cancer.

The HPCX locus was first described by Xu et al (1998) using a set of 360 prostate cancer families. This locus is $50 \mathrm{cM}$ distal to the androgen receptor locus, which maps to Xq11-q12. A previous report from the University of Michigan PCGP provided some additional support of the existence for the HPCX locus with positive NPL $Z$ scores across the candidate region. However, 11
African American families demonstrated no evidence of HPCX linkage with negative NPL $Z$ scores across the entire candidate region (Lange et al, 1999). Addition of 19 more families in this report has resulted in positive, although not statistically significant, NPL $Z$ scores using these same markers. Unfortunately, some of the families described here exhibit only male-to-male transmission of disease. Thus, the stratifications result in small sets of families that limit the conclusions that can be drawn from this analysis.

Regarding the HPC20 locus, 14 African American prostate cancer families from the PCGP have previously been shown to provide evidence for prostate cancer linkage to this locus with a $Z_{\mathrm{lr}}$ of 1.99 between markers D20S893 and D20S120 $(P=0.023)$ (Bock et al, 2001), whereas the 14 JHU families revealed negative NPL $Z$ scores using a similar set of markers. Despite these conflicting results, the combined analysis of the 27 African American families reported herein reveals suggestive evidence of linkage to HPC20 with a peak multipoint NPL $Z$ score of 1.04 near D20S893 $(P=0.15)$. The subsets of African American families providing the greatest evidence for linkage to HPC20 contains families with evidence of male-to-male transmission $(Z=1.64, P=0.05)$ and the families with average of prostate cancer diagnosis $<65$ years $(Z=1.60, P=0.05)$. This contrasts with the initial report describing HPC2O in which the subset with the strongest evidence of linkage to chromosome 20 markers was the 19 white families with $<5$ affected family members, average age of prostate cancer diagnosis $>66$ years and no evidence of male-to-male transmission (Berry et al, 2000b).

It should be noted that two African American JHU families included in this report were also included in the original study by Smith et al. (Smith et al, 1996), which suggested the importance of HPC1 and HPCX in prostate cancer susceptibility. Removing these two families from this current analysis resulted in slightly reduced statistical significance estimates within these regions. For example, the statistical significance of the evidence for linkage at marker D1S413 in families with male-to-male transmission changed very modestly (from $P=0.04$ to $P=0.07$ ). Given the limited number of currently available African American pedigrees, we have chosen to include these two families in the analyses of HPC1 and HPCX described in this report.

In conclusion, this combined analysis of 33 African American prostate cancer families provides continued support for the HPC1 and HPC20 loci as potentially important contributors to prostate cancer susceptibility in this population. Analysis of these additional African American prostate cancer families now provides some evidence that HPCX may contribute to prostate cancer susceptibility in this racial subgroup. Additionally, some new evidence for the PCAP locus was identified particularly among families with early-onset prostate cancer. Clearly, given the still relatively small sample size of the current study and the resulting modest power to detect linkage when present, no firm conclusions should be drawn regarding the other candidate regions in regards to susceptibility in the African American population. Continued support for collection of DNA samples from African American prostate cancer families and genome-wide analyses should help illuminate the predisposing genes in this high-risk population. However, given the relative difficulty in ascertaining African American pedigrees, it is imperative that additional cooperative studies such as this be undertaken to increase our ability to localise and assess the role of prostate cancer susceptibility genes in this population.

\section{ACKNOWLEDGEMENTS}

This research was supported by the following grants from the National Institutes of Health: P50 CA52836 (SPORE) (WBI), SPORE Grant P50 CA69568 (SPORE) (KAC) and R01 CA79596 (KAC) as well as a grant from the Department of Defense (WBI). 


\section{REFERENCES}

Berry R, Schaid DJ, Smith JR, French AJ, Schroeder JJ, McDonnell SK, Peterson BJ, Wang ZY, Carpten JD, Roberts SG, Tester DJ, Blute ML, Trent JM, Thibodeau SN (2000a) Linkage analyses at the chromosome 1 loci 1q24-25 (HPC1), 1q42.2-43 (PCAP), and 1p36 (CAPB) in families with hereditary prostate cancer. Am J Hum Genet 66: 539-546

Berry R, Schroeder JJ, French AJ, McDonnell SK, Peterson BJ, Cunningham JM, Thibodeau SN, Schaid DJ (2000b) Evidence for a prostate cancersusceptibility locus on chromosome 20. Am J Hum Genet 67: 82-91

Berthon P, Valeri A, Cohen-Akenine A, Drelon E, Paiss T, Wohr G, Latil A, Millasseau P, Mellah I, Cohen N, Blanche H, Bellane-Chantelot C Demenais F, Teillac P, Le Duc A, de Petriconi R, Hautmann R, Chumakov I, Bachner L, Maitland NJ, Lidereau R, Vogel W, Fournier G, Mangin P, Cussenot O (1998) Predisposing gene for early-onset prostate cancer, localized on chromosome 1q42.2-43. Am J Hum Genet 62: 1416-1424

Bock CH, Cunningham JM, McDonnell SK, Schaid DJ, Peterson BJ, Pavlic RJ, Schroeder JJ, Klein J, French AJ, Marks A, Thibodeau SN, Lange EM, Cooney KA (2001) Analysis of the prostate cancer-susceptibility locus HPC20 in 172 families affected by prostate cancer. Am J Hum Genet 68: $795-801$

Bratt O (2002) Hereditary prostate cancer: clinical aspects. J Urol 168: $906-913$

Cancel-Tassin G, Latil A, Valeri A, Mangin P, Fournier G, Berthon P, Cussenot O (2001) PCAP is the major known prostate cancer predisposing locus in families from south and west Europe. Eur J Hum Genet 9: $135-142$

Carpten J, Nupponen N, Isaacs S, Sood R, Robbins C, Xu J, Faruque M, Moses T, Ewing C, Gillanders E, Hu P, Bujnovszky P, Makalowska I, Baffoe-Bonnie A, Faith D, Smith J, Stephan D, Wiley K, Brownstein M, Gildea D, Kelly B, Jenkins R, Hostetter G, Matikainen M, Schleutker J, Klinger K, Connors T, Xiang Y, Wang Z, De Marzo A, Papadopoulos N, Kallioniemi OP, Burk R, Meyers D, Gronberg H, Meltzer P, Silverman R, Bailey-Wilson J, Walsh P, Isaacs W, Trent J (2002) Germline mutations in the ribonuclease $\mathrm{L}$ gene in families showing linkage with HPC1. Nat Genet 30: $181-184$

Chen H, Griffin AR, Wu YQ, Tomsho LP, Zuhlke KA, Lange EM, Gruber SB, Cooney KA (2002) RNASEL mutations in hereditary prostate cancer. J Med Genet, 40: e21

Cooney KA, McCarthy JD, Lange E, Huang L, Miesfeldt S, Montie JE, Oesterling JE, Sandler HM, Lange K (1997) Prostate cancer susceptibility locus on chromosome 1q: a confirmatory study. J Natl Cancer Inst 89: 955-959

Gibbs M, Stanford JL, McIndoe RA, Jarvik GP, Kolb S, Goode EL, Chakrabarti L, Schuster EF, Buckley VA, Miller EL, Brandzel S, Li S, Hood L, Ostrander EA (1999) Evidence for a rare prostate cancersusceptibility locus at chromosome 1p36. Am J Hum Genet 64: 776-787

Gronberg H, Isaacs SD, Smith JR, Carpten JD, Bova GS, Freije D, Xu J, Meyers DA, Collins FS, Trent JM, Walsh PC, Isaacs WB (1997)
Characteristics of prostate cancer in families potentially linked to the hereditary prostate cancer 1 (HPC1) locus. JAMA 278: $1251-1255$

Hayes RB, Liff JM, Pottern LM, Greenberg RS, Schoenberg JB, Schwartz AG, Swanson GM, Silverman DT, Morris Brown L, Hoover RN, Fraumeni JF (1995) Prostate cancer risk in US blacks and whites with a family history of cancer. Int J Cancer 60: $361-364$

Jemal A, Thomas A, Murray T, Thun M (2002) Cancer statistics, 2002. CA Cancer J Clin 52: 23-47

Kruglyak L, Daly MJ, Reeve-Daly MP, Lander ES (1996) Parametric and nonparametric linkage analysis: a unified multipoint approach. Am J Hum Genet 58: $1347-1363$

Lange EM, Chen H, Brierley K, Perrone EE, Bock CH, Gillanders E, Ray ME, Cooney KA (1999) Linkage analysis of 153 prostate cancer families over a 30-cM region containing the putative susceptibility locus HPCX. Clin Cancer Res 5: 4013-4020

Monroe KR, Yu MC, Kolonel LN, Coetzee GA, Wilkens LR, Ross RK, Henderson BE (1995) Evidence of an X-linked or recessive genetic component to prostate cancer risk. Nat Med 1: 827-829

Smith JR, Freije D, Carpten JD, Gronberg H, Xu J, Isaacs SD, Brownstein MJ, Bova GS, Guo H, Bujnovszky P, Nusskern DR, Damber JE, Bergh A, Emanuelsson M, Kallioniemi OP, Walker-Daniels J, Bailey-Wilson JE, Beaty TH, Meyers DA, Walsh PC, Collins FS, Trent JM, Isaacs WB (1996) Major susceptibility locus for prostate cancer on chromosome 1 suggested by a genome-wide search. Science 274: 1371-1374

Whittemore AS, Wu AH, Kolonel LN, John EM, Gallagher RP, Howe GR, West DW, Teh C-Z, Stamey T (1995) Family history and prostate cancer risk in Black, White and Asian men in the United States and Canada. Am J Epidemiol 141: $732-740$

$\mathrm{Xu} \mathrm{J}$ (2000) Combined analysis of hereditary prostate cancer linkage to 1q24-25: results from 772 hereditary prostate cancer families from the International Consortium for Prostate Cancer Genetics. Am J Hum Genet 66: $945-957$

Xu J, Meyers D, Freije D, Isaacs S, Wiley K, Nusskern D, Ewing C, Wilkens E, Bujnovszky P, Bova GS, Walsh P, Isaacs W, Schleutker J, Matikainen M, Tammela T, Visakorpi T, Kallioniemi OP, Berry R, Schaid D, French A, McDonnell S, Schroeder J, Blute M, Thibodeau S, Gronberg H, Emanuelsson M, Damber JE, Bergh A, Jonsson BA, Smith J, Bailey-Wilson J, Carpten J, Stephan D, Gillanders E, Admudson I, Kainu T, Freas-Lutz D, Baffoe-Bonnie A, Van Aucken A, Sood R, Collins F, Brownstein MJ, Trent J (1998) Evidence for a prostate cancer susceptibility locus on the $\mathrm{X}$ chromosome. Nat Genet 20: $175-179$

Xu J, Zheng SL, Chang B, Smith JR, Carpten JD, Stine OC, Isaacs SD, Wiley KE, Henning L, Ewing C, Bujnovszky P, Bleeker ER, Walsh PC, Trent JM, Meyers DA, Isaacs WB (2001) Linkage of prostate cancer susceptibility loci to chromosome 1. Hum Genet 108: 335-345 